\title{
In Vitro Antimicrobial Susceptibility of Escherichia coli Isolates from Clinical Bovine Mastitis in Finland and Israel
}

\author{
T. Lehtolainen, ${ }^{*}$ A. Shwimmer, $†$ N. Y. Shpigel, $\dagger$ \\ T. Honkanen-Buzalski, $\ddagger$ and S. Pyörälä* \\ *University of Helsinki \\ Faculty of Veterinary Medicine \\ FIN-04920 Saarentaus, Finland \\ tHebrew University of Jerusalem \\ Koret School of Veterinary Medicine \\ Rehovot 76100, Israel \\ $\ddagger$ National Veterinary and Food Research Institute \\ FIN-00580 Helsinki, Finland
}

Abbreviation key: DHS = dihydrostreptomycin, MIC $=$ minimal inhibition concentration, $\mathbf{M I C}_{50}=$ minimal inhibition concentration for $50 \%$ of isolates tested, $\mathbf{M I C}_{\mathbf{9 0}}=$ minimal inhibition concentration for $90 \%$ of isolates tested, $\mathbf{T S}=$ trimethoprim-sulfadiazine

\section{INTRODUCTION}

Environmental bovine mastitis caused by coliform bacteria has increased in many herds and countries (Lam, 1996). The great majority of these coliform bacteria belong to Escherichia coli. Escherichia coli originate from the cow's environment and infect the udder via the teat canal (Eberhart, 1979). The proportion of coliform mastitis in clinical mastitis varies between countries. In Finland, less than $20 \%$ of clinical mastitis is caused by coliforms (Pyörälä and Honkanen-Buzalski, 1994), whereas in Israel more than 60\% (Shpigel et al., 1998) of clinical mastitis is caused by coliforms. This is probably the result of differences in environmental factors and herd management. In Finland, small herds are mostly kept indoors and confined to stanchion barns. In Israel, large herds with very high yielding cows are kept in loose housing systems in hot weather.

Broad-spectrum antimicrobial agents are generally used to treat coliform mastitis (Andersson, 1989; Erskine et al., 1991), although there is no convincing evidence that antimicrobials are an effective (Erskine et al., 1992; Pyörälä et al., 1994; Pyörälä and Pyörälä, 1998; Erskine, 2000). Antibiotic therapy may be useful if the host response is compromised, as during the puerperal period, or if the growth of bacteria in the milk is abundant (Erskine et al., 2002; Rantala, 2002). However, the use of antimicrobial agents causes selection pressure toward antimicrobial resistance among bacteria (Aarestrup, 1999; Prescott, 2000), and resistance to one antimicrobial agent can be linked with resistance
Received April 14, 2003.

Accepted June 25, 2003.

Corresponding author: T. Lehtolainen; e-mail: tanja.lehtolainen@ helsinki.fi. 


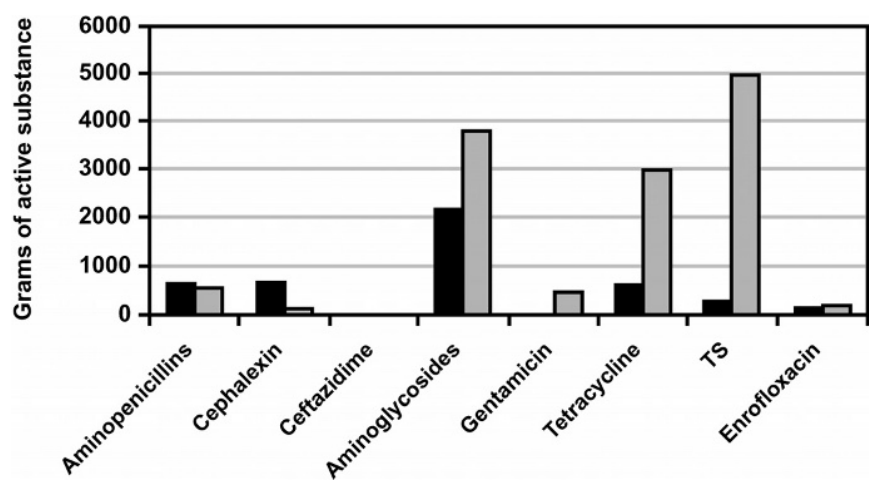

Figure 1. Amounts of aminopenicillins, cephalexin, ceftazidime, aminoglycosides, gentamicin, tetracycline, trimethoprim-sulfadiazine (TS), and enrofloxacin used for dairy cows in Finland ${ }^{1}$ (solid bars) and in Israel ${ }^{2}$ (gray bars). The data is shown as grams of active antimicrobial per thousand cows. ${ }^{1}$ Data from Finish Ministry of Agriculture, estimated from statistics from the National Agency of Medicines. ${ }^{2}$ Data from Hacklait, the Israeli wholesaler.

against other antimicrobials (Levy et al., 1976; Prescott, 2000). The resistance patterns of the bacterial populations can vary between countries or even herds, which may reflect the quantitative and qualitative aspects of antimicrobial treatment (Aarestrup, 1999; DANMAP, 2001; Österbland et al., 2001).

The use of antimicrobial substances in animal therapy has been recorded in Finland since 1994 (Figure 1). $\beta$-Lactam antibiotics are the most commonly used antimicrobial agents for cattle (Helin et al., 2000). Mastitis is the main indication for the use of antimicrobial agents in dairy cows (Honkanen-Buzalski and Huovinen, 1999). Most mastitis cases are caused by grampositive bacteria and have mainly been treated with systemically administered penicillin, or sometimes with intramammarily administered aminoglycosides combined with $\beta$-lactam antimicrobials or oxytetracycline. Acute clinical mastitis caused by gram-negative bacteria is often treated systemically with trimethoprim-sulphonamide or enrofloxacin.

In Israel, no systematic surveillance of antimicrobial administration for animals exists. However, all medicine for cattle is supplied by the wholesaler, who keeps annual records of consumption and the types of medicine used in dairy herds (Figure 1). The main indications for antimicrobial treatments in dairy herds are metritis, and mastitis caused by coliform bacteria. Antimicrobials used are mainly tetracycline, gentamicin, and a trimethoprim-sulfonamide combination. Penicillin combined with dihydrostreptomycin (DHS) is also used parenterally for foot problems and intramammarily for dry cow treatment.

The incidence of $E$. coli mastitis, herd management, and the use of antimicrobial agents differ between Fin- land and Israel. Consequently, the aim of this study was to determine the in vitro antimicrobial susceptibility of $E$. coli bacteria isolated from clinical mastitis in Finland and Israel, and to identify possible differences in susceptibility of the isolates between these two countries.

\section{MATERIALS AND METHODS}

\section{Bacterial Isolates}

A total of $200 \mathrm{E}$. coli isolates from acute clinical cases of bovine mastitis were studied: 100 from Finland and 100 from Israel. The isolates were collected from 90 dairy farms in Finland and from 27 farms in Israel. A milk sample was aseptically taken from the affected quarter of the cow before any antimicrobial treatment and cultured using standard methods. Isolates were stored in a semi-solid broth (Lab Lemco broth, Oxoid, Hampshire, UK) at room temperature. They were presumptively identified as $E$. coli by phenotypic methods, including colony morphology on blood agar, Gram stain, and growth on EMB agar, and identification was later confirmed using the API 20E test (bioMérieux, Marcy l'Etoile, France) at the National Veterinary and Food Research Institute, Kuopio, Finland.

Escherichia coli ATCC 25922, Enterococcus faecalis ATCC 29212, and Staphylococcus aureus ATCC 29213 (NCCLS, 1999) were used as reference strains. Both test isolates and reference strains were prepared in suspension at a concentration of $10^{7} \mathrm{cfu} / \mathrm{ml}$, as recommended by the National Committee for Clinical Laboratory Standards (NCCLS, 1999).

\section{Antimicrobial Agents}

Animal inhibition concentration (MIC) values of the isolates were analyzed for eight different antimicrobials: ampicillin (ampicillin sodium salt, Sigma Chemical Co., St. Louis, MO, lot 127H0285), cephalexin (cephalexin hydrate, Sigma, lot 24H0420), ceftazidime (ceftazidime pentahydrate, Sigma, lot 35H0473), DHS (dihydrostreptomycin sesquisulfate salt, Sigma, lot $66 \mathrm{H} 04142$ ), gentamicin (gentamicin sulfate, Sigma, lot 27H0744), tetracycline (tetracycline, Sigma, lot 38H1324), trimethoprim-sulfadiazine (TS) (trimethoprim, Sigma, lot 105H0136; sulfadiatsin, Sigma, lot 96H1175), and ciprofloxacin (ciprofloxacin* $\mathrm{HCl}$, Bayer Ag, Levekusen, Germany, lot 303477A) by an agar dilution method (NCCLS, 1999). The antimicrobial stock solutions were prepared and diluted as recommended by their respective manufacturers to a concentration of $1280 \mu \mathrm{g} / \mathrm{ml}$. The TS was made up to a ratio of $1: 5$. The actual concentrations for both compounds in the stock solution were $213.33 \mu \mathrm{g} / \mathrm{ml}$ for trimethoprim and $1066.66 \mu \mathrm{g} / \mathrm{ml}$ for sulfadiazine. 
The stock solutions of each antibiotic were further diluted and mixed with molten Mueller-Hinton agar. The final concentrations ranged in two-step dilutions from $128 \mu \mathrm{g} / \mathrm{ml}$ to $0.5 \mu \mathrm{g} / \mathrm{ml}$ for ampicillin, cephalexin, DHS, tetracycline, and TS; from $64 \mu \mathrm{g} / \mathrm{ml}$ to $0.25 \mu \mathrm{g} /$ $\mathrm{ml}$ for gentamicin; and from $16 \mu \mathrm{g} / \mathrm{ml}$ to $0.0625 \mu \mathrm{g} /$ $\mathrm{ml}$ for ciprofloxacin and ceftazidime, which also had a concentration of $32 \mu \mathrm{g} / \mathrm{ml}$. These antimicrobials are all options or group representatives of potential subtances for the treatment of coliform mastitis. Ciprofloxacin was chosen to represent enrofloxacin since enrofloxacin is extensively metabolized to ciprofloxacin in cattle (Kaartinen et al., 1995).

\section{Antimicrobial Susceptibility Testing}

All isolates were tested at the National Veterinary and Food Research Institute, Helsinki, Finland. Antimicrobial agars were inoculated with the respective bacterial suspensions using the Automatic Multipoint Inoculator (Mast Diagnostics Ltd., Merseyside, U.K.) with $3-\mathrm{mm}$ metal pins. The volume of the suspension drop was $2 \mu \mathrm{l}$, and it contained $2 \times 10^{4}$ cfu of $E$. coli (NCCLS, 1999). Growth of the inoculates was determined after incubation at $37^{\circ} \mathrm{C}$ for $20 \mathrm{~h}$ by observing the agar plates directly from above. The MIC value was recorded as the lowest concentration of the antibiotic to inhibit growth of the inoculated bacteria (NCCLS, 1999).

The MIC breakpoint values used for in vitro susceptibility were $8 \mu \mathrm{g} / \mathrm{ml}$ for ampicillin, cephalexin, DHS, and $\mathrm{TS} ; 4 \mu \mathrm{g} / \mathrm{ml}$ for gentamicin and tetracycline; $0.25 \mu \mathrm{g} / \mathrm{ml}$ for ciprofloxacin; and $2 \mu \mathrm{g} / \mathrm{ml}$ for ceftazidime (NCCLS, 1999). The breakpoint values for DHS, ciprofloxacin, and ceftazidime were set at the level of streptomycin, enrofloxacin, and ceftiofur, respectively, given in the NCCLS document. An isolate was considered resistant to a certain antimicrobial if the MIC value were higher than the MIC breakpoint value for susceptibility of that antimicrobial. Values for MIC for 50 and $90 \%$ of isolates tested (MIC $_{\mathbf{9 0}}$ and $\mathbf{M I C}_{\mathbf{5 0}}$ ) were calculated for all antimicrobials tested.

\section{Statistical Analysis}

Differences in the frequencies of resistance to antimicrobials among the isolates were determined by Pearson's chi-squared test. A value of $P<0.05$ was considered to be significant.

\section{RESULTS}

The MIC values of $E$. coli isolates from both Finland and Israel were similar and relatively low (Table 1).
The majority of the isolates were susceptible to the antimicrobial agents studied. A total of $30 \%$ of Finnish and $24 \%$ of Israeli isolates were resistant to one or more antimicrobials. Of the Finnish isolates, $16 \%$ were resistant to cephalexin, compared with only $3 \%$ of Israeli isolates; however, only one Finnish isolate had a high MIC value ( $>128 \mu \mathrm{g} / \mathrm{ml})$; other isolates classified as resistant, according to the NCCLS breakpoint, were at the borderline. For the other antimicrobial agents, the proportion of resistant strains was higher for Israeli isolates than for Finnish ones. Ten percent of Israeli isolates and $7 \%$ of Finnish isolates were resistant to ampicillin, 13 and 9\% to DHS, 15 and $14 \%$ to tetracycline and 4 and $2 \%$ to TS, respectively. No gentamicin, ciprofloxacin-, and ceftazidime-resistant isolates were detected. The difference in the number of resistant isolates between the two countries was statistically significant $(P<0.01)$ for cephalexin only.

In total, 32 isolates (16\%), 20 from Finland and 12 from Israel, were resistant to only one antimicrobial, namely cephalexin, tetracycline, DHS, or ampicillin (Table 2). Twenty-two isolates (11\%), 10 Finnish and 12 Israeli, were resistant to two or more antibiotics in 10 different combinations. From the total amount of resistant isolates, $41 \%$ were multiresistant. Tetracycline was included in all but one multiresistant pattern; DHS and ampicillin were also often present. Most of the multiresistant isolates had very high MIC values, whereas most of those that were resistant to only one tested antimicrobial had MIC values close to the susceptibility breakpoint.

Whereas $\mathrm{MIC}_{50}$ values for Finnish and Israeli isolates did not differ markedly, differences were present between MIC $_{90}$ values (Table 1). For cephalexin, the Finnish isolates had one dilution higher $\mathrm{MIC}_{90}$ value $(16 \mu \mathrm{g} /$ $\mathrm{ml})$ than Israeli isolates $(8 \mu \mathrm{g} / \mathrm{ml})$, whereas for ceftazidime and TS, the MIC $_{90}$ values were one dilution higher among Israeli ( 0.5 and $4 \mu \mathrm{g} / \mathrm{ml}$, respectively) vs. Finnish isolates ( 0.25 and $2 \mu \mathrm{g} / \mathrm{ml}$, respectively). For DHS and tetracycline, the Israeli isolates had clearly higher $\mathrm{MIC}_{90}$ values (32 and $64 \mu \mathrm{g} / \mathrm{ml}$, respectively) than the Finnish isolates $(8 \mu \mathrm{g} / \mathrm{ml}$ for both).

\section{DISCUSSION}

The in vitro antimicrobial susceptibility of the examined E. coli isolates from bovine mastitis was high compared with results from previous studies (Bishop et al., 1980; Sogaard, 1982; Anderson, 1989; Trolldenier, 1995). However, because some of these studies have used different susceptibility testing methods, comparisons should be made with caution. Only $27 \%$ of our isolates were resistant to one or more antimicrobial agents. The most common resistance was to tetracy- 
Table 1. Cumulative percentages of MIC values of the Escherichia coli isolates from bovine mastitis from Finland (n = 100) and Israel (n $=100$ ). The MIC susceptibility breakpoint value of each antimicrobial is indicated in bold. ${ }^{1}$

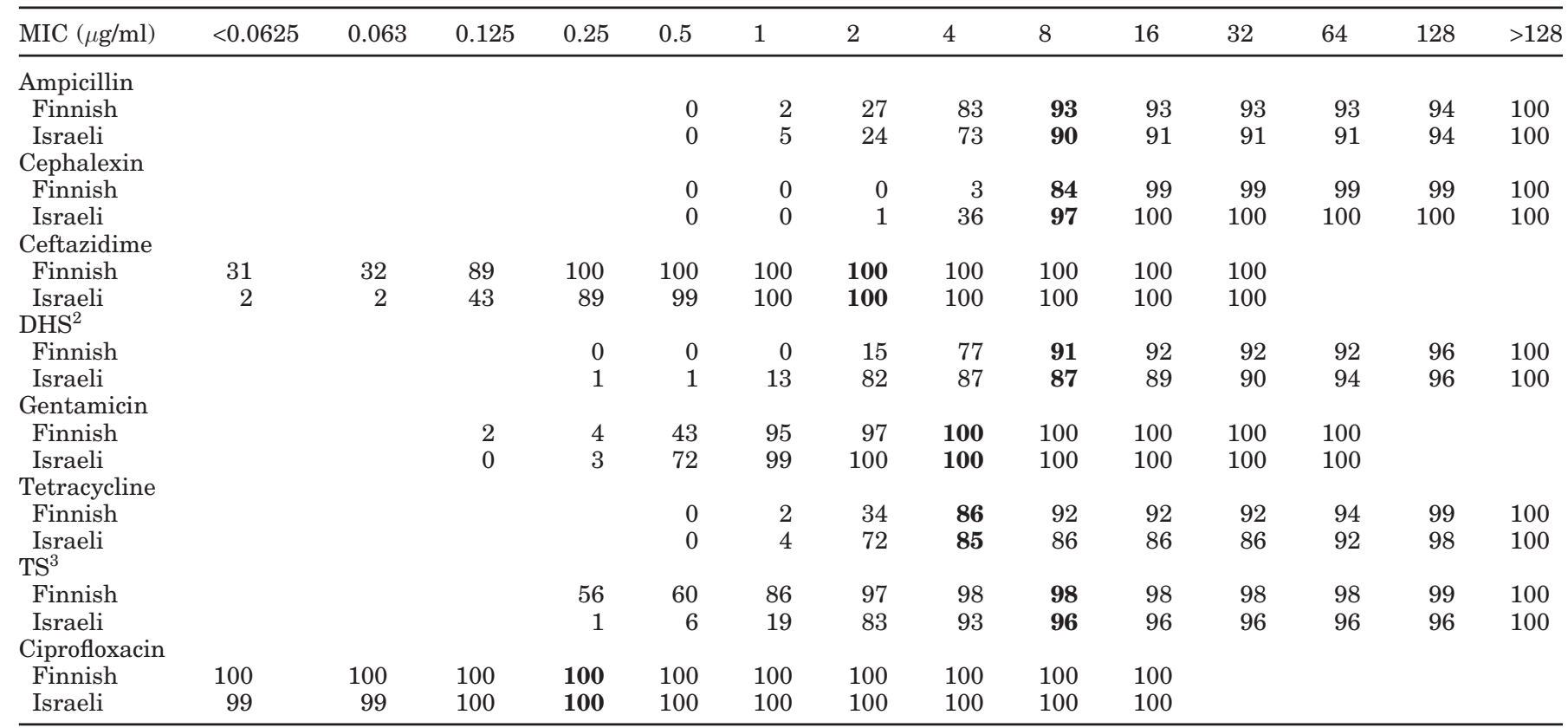

${ }^{1} \mathrm{MIC}=$ minimal inhibition concentration.

${ }^{2} \mathrm{DHS}=$ dihydrostreptomycin.

${ }^{3} \mathrm{TS}=$ trimethoprim-sulfadiazine.

cline, accounting for $15 \%$ of all isolates. This is a relatively low figure as compared with other published studies, where the proportion of resistant isolates has ranged from 26 to $74 \%$ (Sogaard, 1982; Anderson, 1989; Trolldenier, 1995; DANMAP, 2001). We found no isolates resistant to gentamicin, although $9 \%$ resistance was reported in an earlier US study (Anderson, 1989). In addition, the proportion of resistant isolates to ampicillin and DHS in our study, 9 and 11\%, were clearly lower than the corresponding figures in the previous studies: 18 to 82\% (Bishop et al., 1980; Sogaard, 1982; Anderson, 1989) and 58\% (Davidson, 1982), respec-

Table 2. Resistance patterns among the Escherichia coli strains isolated from bovine mastitis in Finland and in Israel.

\begin{tabular}{|c|c|c|c|c|c|c|}
\hline \multicolumn{5}{|c|}{ Resistance patterns } & \multicolumn{2}{|c|}{ Number of isolates } \\
\hline & & & & & \multirow{2}{*}{$\frac{\text { Finnish }}{1}$} & \multirow{2}{*}{$\begin{array}{c}\text { Israeli } \\
0\end{array}$} \\
\hline Tetracycline & $\mathrm{DHS}^{1}$ & Ampicillin & Cephalexin & $\mathrm{TS}^{2}$ & & \\
\hline Tetracycline & DHS & Ampicillin & Cephalexin & & 1 & 0 \\
\hline Tetracycline & DHS & Ampicillin & $\mathrm{TS}$ & & 0 & 4 \\
\hline Tetracycline & DHS & Ampicillin & & & 0 & 1 \\
\hline Tetracycline & DHS & Cephalexin & & & 1 & 0 \\
\hline Tetracycline & DHS & TS & & & 1 & 0 \\
\hline Tetracycline & DHS & & & & 1 & 4 \\
\hline Tetracycline & Ampicillin & Cephalexin & & & 1 & 0 \\
\hline Tetracycline & Ampicillin & & & & 2 & 1 \\
\hline DHS & Ampicillin & & & & 2 & 2 \\
\hline Tetracycline & & & & & 6 & 5 \\
\hline DHS & & & & & 2 & 2 \\
\hline Ampicillin & & & & & 0 & 2 \\
\hline Cephalexin & & & & & 12 & 3 \\
\hline Negative & & & & & 70 & 76 \\
\hline Total & & & & & 100 & 100 \\
\hline
\end{tabular}

${ }^{1} \mathrm{DHS}=$ dihydrostreptomycin.

${ }^{2} \mathrm{TS}=$ trimethoprim-sulfadiazine. 
tively. Among our resistant isolates, $41 \%$ were multiresistant, a slightly lower figure than that found in a previous report, where $50 \%$ of the resistant isolates were multiresistant (Sogaard, 1982).

Some studies have shown that antibiotic usage has directly contributed to an increased prevalence of resistance (Aarestrup, 1999; DANMAP, 2001). The use of antimicrobial agents in dairy herds is well controlled in both Finland and Israel. Antimicrobials are used in cattle for therapeutic purposes only; subtherapeutic or growth-promoting use is prohibited. The total amounts of antimicrobial agents consumed in dairy herds have remained relatively low compared with some other areas (Figure 1) (DANMAP, 2001; Gorbach, 2001). This could be one reason for the low level of resistance found among $E$. coli bacteria isolated from bovine mastitis compared with other studies.

Coliform mastitis is most often caused by fecal flora originating from the same or another cow (Linton et al., 1984). Coliform bacteria isolated from mastitis may thus reflect the general resistance situation in the herd and can be considered more as an indicator of bacteria than of specific pathogens of the udder. All antimicrobial use in the herd may affect the resistance of coliforms. The more resistant strains of $E$. coli are proposed to originate from calves, due to their greater exposure to antibiotics (Linton et al., 1984). However, neither in Finland nor in Israel are calves excessively exposed to antibiotics because of the restriction imposed on subtherapeutic or growth-promoting use. In Israel, calves are housed separately from cows so they do not share the same bacterial reservoir. In Finland, calves are kept with dairy cattle in the same building. The antimicrobial agents traditionally used for treatment of calves have been DHS, oxytetracycline, and the trimethoprimsulfonamide combination (Honkanen-Buzalski and $\mathrm{Hu}-$ ovinen, 1999). These might have affected the resistance of Finnish isolates by increasing the presence of these antimicrobial agents in the cows' environment.

The only statistically significant difference between the susceptibility of Finnish and Israeli isolates was for cephalexin. In Finland, this first-generation cephalosporin is commonly used as a first choice for intramammary treatment of mastitis, and the total amount used is higher than that in Israel (Figure 1). This could explain the higher proportion of resistant isolates and the slightly higher $\mathrm{MIC}_{50}$ value compared with Israeli isolates. In both countries, tetracycline, DHS, and ampicillin showed the highest resistance, and they were also the most frequently found antimicrobial agents in the multiresistant patterns. Israeli isolates had a twodilution higher $\mathrm{MIC}_{90}$ value for DHS and a four-dilution higher $\mathrm{MIC}_{90}$ value for tetracycline. These antimicro- bial agents are used much more often and in greater amounts in Israel than in Finland (Figure 1).

From tetracycline-, DHS- and ampicillin-resistant isolates, 62,82 , and $88 \%$, respectively, were also resistant to some other antimicrobial. Those antimicrobial agents are often found together in multiresistant patterns, possibly indicating transferable resistance (Österbland et al., 2000; Oppegaard et al., 2001). Multiresistant bacteria also tend to maintain their resistance to a particular antimicrobial even when that antimicrobial is absent from the environment if the other antimicrobials to which the resistance is linked are still present (Levy, 1992; Prescott, 2000; Galland et al., 2001). Not only the amount of antimicrobials used, but also the frequency of use, may be relevant for the emergence of resistance (Levy, 1992).

In conclusion, in vitro susceptibility of $E$. coli isolated from mastitis in Finland and Israel was high, which may indicate the low total use of antimicrobial agents in the cows' environment in these countries. Differences in MIC profiles may reflect differences in the use of antimicrobial agents. Susceptibility of $E$. coli isolated from mastitis could be considered to be an indicator of the general susceptibility situation among bacteria of the herd.

\section{ACKNOWLEDGMENTS}

We would like to thank Hannu Sipilä for excellent assistance with the laboratory work. This work was supported by the Finnish Academy and by a grant from the Walter Erhrstöm Foundation.

\section{REFERENCES}

Aarestrup, F. M. 1999. Association between the consumption of antimicrobial agents in animal husbandry and the occurrence of resistant bacteria among food animals. Int. J. Antimicrob. Agents 12:279-285.

Anderson, K. L. 1989. Therapy for acute mastitis. Comp. Contin. Educ. 9:1125-1133.

DANMAP. 2001. Use of Antimicrobial Agents and Occurrence of Antimicrobial Resistance in Bacteria from Food Animals, Foods and Humans in Denmark. The Danish Integrated Antimicrobial Resistance Monitoring and Research Programme, Copenhagen, Denmark.

Bishop, J. R., A. B. Bodine, and J. J. Janzen. 1980. Sensitivities to antibiotics and seasonal occurrence of mastitis pathogens. J. Dairy Sci. 63:1134-1137.

Davidson, J. N., J. G. Babish, and G. M. Dunny. 1982. Bovine mastitis: Antimicrobial resistance patterns. JAVMA 180:153-155.

Eberhart, R. J. 1979. Coliform mastitis-a review. J. Dairy Sci. 62:1-22.

Erskine, R. J. 2000. Antimicrobial use in bovine mastitis. Pages 712734 in Antimicrobial Therapy in Veterinary Medicine. 3rd ed. J. F. Prescott, J. D. Baggot, and R. D. Walker, eds. Iowa State Univ. Press, Ames.

Ersikine, R. J., P. C. Barlett, J. L. VanLente, and C. R. Phipps. 2002. Efficacy of systemic ceftiofur as a therapy for severe clinical mastitis in dairy cows. J. Dairy Sci. 85:2571-2572. 
Erskine, R. J., J. W. Tyler, M. G. Riddel, and R. G. Wilson. 1991. Theory, use, and realties of efficacy and food safety of antimicrobial treatment of acute coliform mastitis. JAVMA 198:980-984.

Erskine, R. J., R. C. Wilson, M. G. Riddel, J. W. Tyler, H. J. Spears, and B. S. Davis. 1992. Intramammary administration of gentamicin as treatment for experimentally induced Escherichia coli mastitis in cows. Am. J. Vet. Res. 53:375-381.

Galland, J. C., D. R. Hyatt, S. S. Crupper, and D. W. Acheson. 2001. Prevalence, antibiotic susceptibility, and diversity of Escherichia coli 0157:H7 isolates from a longitudinal study of beef cattle feedlots. Appl. Environ. Microbiol. 4:1619-1627.

Gorbach, S. L. 2001. Antibiotic use in animal feed-Time to stop. New Engl. J. Med. 345:1202-1203.

Helin, H., T. Voipio, and L. Kaartinen. 2000. The consumption of veterinary medicinal products in 1999-antimicrobials, antiparasiticides and hormones. Finn. Vet. J. 106:693-698.

Honkanen-Buzalski, T., and P. Huovinen. 1999. Bacterial Resistance to Antimicrobial Agents in Finland FINRES 1999. Ministry of Agriculture and Forestry, Food and Health Dept., Helsinki, Finland.

Kaartinen, L., M. Salonen, L. Älli, and S. Pyörälä. 1995. Pharmacokinetics of enrofloxacin after single intravenous, intramuscular and subcutaneous injections in lactating cows. J. Vet. Pharmacol. Ther. 18:357-362.

Lam, T. J. G. M. 1996. Dynamics of bovine mastitis a field study in low somatic cell count herds. Ph.D. Thesis, Univ. Utrecht, Faculteit Diergeneeskunde, Utrecht, Holland.

Levy, S. B. 1992. The Antibiotic Paradox: How Miracle Drugs Are Destroying the Miracle. Plenum Press, New York, NY.

Levy, S. B., G. B. Fitzgerald, and A. B. Macone. 1976. Changes in intestinal flora of farm personnel after introduction of a tetracycline-supplemented feed on a farm. N. Engl. J. Med. 295:583-588.

Linton, A. H., and T. C. Robinson. 1984. Studies on the association of Escherichia coli with bovine mastitis. Br. Vet. J. 140:368-373.

NCCLS. 1999. Performance standards for antimicrobial disk and dilution susceptibility tests for bacteria isolated from animals. Approved standard M31-A. Vol. 19, No. 11. National Committee for Clinical Laboratory Standards, Villanova, PA.
Oppegaard, H., T. M. Steinum, and Y. Wasteson. 2001. Horizontal transfer of a multi-drug resistance plasmid between coliform bacteria of human and bovine origin in a farm environment. Appl. Environ. Microbiol. 8:3732-3734.

Österbland, M., A. Hakanen, R. Manninen, T. Leistevuo, R. Peltonen, O. Meurman, P. Huovinen, and P. Kotilainen. 2000. A between comparison of antimicrobial resistance in enterobacteria in fecalspecies flora. Antimicrob. Agents Chemother. 6:1479-1484.

Österbland, M., K. Norrdahl, E. Korpimäki, and P. Huovinen. 2001. How wild are wild mammals? Nature 409:37-38.

Prescott, J. F. 2000. Antimicrobial drug resistance and its epidemiology. Pages 27-49 in Antimicrobial Therapy in Veterinary Medicine. 3rd ed. J. F. Prescott, J. D. Baggot, and R. D Walker, eds. Iowa State Univ. Press, Ames.

Pyörälä, S., and T. Honkanen-Buzalski. 1994. The status of mastitis in the Nordic countries. Int. Dairy Fed. Mastitis News 19:14-15.

Pyörälä, S., and E. Pyörälä. 1998. Efficacy of parenteral administration of three antimicrobial agents in treatment of clinical mastitis in lacting cows: 487 cases (1989-1995). JAVMA 212:407-412.

Pyörälä, S., L. Kaartinen, H. Käck, and V. Rainio. 1994. Efficacy of two therapy regimes for treatment of experimentally induced Escherichia coli mastitis in the bovine. J. Dairy Sci. 77:453-461.

Rantala, M., L. Kaartinen, E. Välimäki, M. Styrman, M. Hiekkaranta, A. Niemi, L. Saari, and S. Pyörälä. 2002. Efficacy and pharmacokinetics of enrofloxacin and flunixin meglumine for treatment of cows with experimentally induced Escherichia coli mastitis. J. Vet. Pharm. Therap. 25:251-258.

Shpigel, N.Y., M. Winkler, G. Ziv, and A. Saran. 1998. Clinical, bacteriological and epidemiological aspects of clinical mastitis in Israeli dairy herds. Prev. Vet. Med. 35:1-9.

Sogaard, H. 1982. In-vitro antibiotic susceptibility of E. coli isolated from acute and chronic mastitis with reference to clinical efficacy. Nord. Vet. Med. 34:248-254.

Trolldenier, H. 1995. Bacterial resistance in veterinary medicine (Resistenzauswertung veterinärmedizinischer bakterieller Errenger). Bundesinstitut für gesundheitlichen. Verbraucherschutz Veterinärmedizin 10:11-12. 